\title{
Climate Change, Agriculture and Migration: A Survey
}

\author{
Chiara Falco ${ }^{1, *}$ (i) , Franco Donzelli ${ }^{1}$ (i) and Alessandro Olper ${ }^{1,2, *}$ \\ 1 Department of Environmental Science and Policy, University of Milano, 20122 Milano, Italy; \\ franco.donzelli@unimi.it \\ 2 LICOS-Centre for Institution and Economic Performance, KU Leuven, 3000 Leuven, Belgium \\ * Correspondence: chiara.falco@unimi.it (C.F.); alessandro.olper@unimi.it (A.O.); Tel.: +39-02-5031-6481 (A.O.)
}

Received: 25 February 2018; Accepted: 28 April 2018; Published: 3 May 2018

check for updates

\begin{abstract}
This paper proposes a selective review of the classical economics-based literature on climate change and migration, focusing on the extent to which agriculture might be considered a key mediating channel linking climate change to migration. Overall, climate change is expected to have large and negative effects on the global economy. These effects are even more evident whenever the economic sector considered is the agricultural one, particularly in developing countries. Hence, migration can be viewed as a specific form of adaptation implemented by individuals and households, enabling them to cope, among other things, with weather-induced risk. We show that the importance of agriculture emerges from both plenty of micro-level country studies and relatively few macro-level analyses using cross-sectional data over longer time periods. Thus, policy actions targeted to sustainable agriculture and rural development can both help tackle the challenges posed by climate change and create opportunities in the face of growing migration issues. However, we also stress that much of the current evidence is based on statistical associations that have nothing to do with causal inferences. This calls for the use of a more structural approach and more sophisticated research designs, enabling the researchers to better discriminate among different mechanisms concurrently at work. In addition, further research should be addressed to the role played by food security, a complex dimension largely missing in the current debates on climate change and migration.
\end{abstract}

Keywords: climate change; agriculture; migration; adaptation; selective review

\section{Introduction}

The importance of climate change and human mobility has been recently underlined not only by academic researchers, but also by international organizations and political institutions. According to United Nations estimates, the number of international migrants has been rapidly increasing over the last fifteen years, climbing from 173 million people in 2000 to more than 240 million in 2015, with most of the migrants coming from middle-income countries [1].

The intensification of climate change, global warming and weather variability for the coming decades has been predicted by many studies, such as the Stern report [2] and the Intergovernmental Panel on Climate Change [3]. The International Organization for Migration (IOM) has estimated that by mid-century almost 200 million people (which is nearly the number currently estimated for international migrants) might become permanent or temporary environmental migrants, where by this term we mean individuals forced to move (within a country or internationally) in response to climatic shocks. Yet, other studies have suggested that climate change will only lead to minor migration effects [4]. Such conflicting assessments are explained, at least in part, by the fact that the empirical evidence linking climate change to migration still is in its infancy. Moreover, the existing evidence is not free from contradictions due not only to different empirical approaches and identification strategies, 
but even to different definitions of migration and environmental migrants [5]. However, the reasons behind individual migration within or across countries, and the extent to which climate change may be considered as a possible push factor in the migration process, are currently regarded as challenging and sensitive topics [6].

In general, individuals' migration is mainly motivated by socio-economic factors, as migrants aim to increase their incomes, to reunite with family members who have already experienced a migration process, or to deal with bad political institutions or conflicts. Part of the literature has considered migration as a possible insurance mechanism towards environmental disasters and climate change, when people do not have alternative adaptation strategies and can incur migration costs $[7,8]$. In fact, climate vulnerability underlies many elements that might affect migration decisions, as individuals can overcome their negative income variations due to weather shocks either through cross-country migration or by moving within the country. However, liquidity problems and other forms of mobility constraints, when exacerbated by climate shocks, can reduce the propensity to migrate and even trap population in their places of origin.

Even if one could easily document that there exists a link between climate change and human mobility, it is more complex to understand the mechanisms through which the former phenomenon affects the latter. This is because the impact of climatic shocks will depend on both their intensity and the extent to which climate changes act upon migration either directly, or indirectly through other factors. Clearly, understanding the underlying mechanisms and different channels at work between climate change and migration is crucial to formulate evidence-based policy recommendations [9].

Within the recent literature on climate change and migration, the impact of rising temperature and precipitation on agricultural outcomes has been indicated as one of the possible key factors of migration push [10]. This is because, first, agriculture is one of the main sources of income and employment in rural areas of developing countries where most migrants are coming from. Second, it is because agriculture is, by far, the sector most affected by climate variations, since short- and long-term effects of climate change have significant impacts on agricultural productivity, rural livelihoods, and food security and, indirectly, migration flows [11]. Third, the vulnerability to climate change of many rural areas in developing countries is exacerbated by the consideration that more than half of food calories produced globally come from areas in the developing world, where the density of (small) farming households is very high [12].

History provides several interesting examples of negative climatic shocks inducing people to migrate, with agriculture apparently playing a key role. For example, how climate triggered migration from southwest Germany to US during the 19th century is documented by [13]. In this historical analysis, the effect of cold weather on high grain price appears to be central to German migration, showing considerable influence of weather conditions on harvests, and consequently on out-migration. Perhaps, one of the most studied climate and migration events is the so-called "American Dust Bowl", namely the large dust storms that affected many US and Canadian counties in the 1930s, also as an effect of over-exploitation of agricultural land. As shown by [14], the permanent soil erosion and the agricultural costs induced by these storms have been partially mitigated by both short- and long-run out-migration from the most to the less affected counties.

The aim of this paper is to present a selective review of a small but rising economic literature, explaining why agriculture can be considered as the key link between climate change and migration. This means to assume that climate change affects migration mainly indirectly, through its effect on agricultural productivity, rural livelihoods, and food (in-)security. In organizing the material, we focus explicitly on classical economics-based researches with empirical (econometric) content. Thus, we do not cover qualitative/ethnographic studies. We focus the attention mainly on articles published in leading economics journals and in top field economics journals applied to development issues, environment, and the agricultural sector. In addition, we consider top multidisciplinary journals (e.g., Nature and Proceedings of the National Academy of Sciences-PNAS) focusing explicitly on environmental/climate change and migration issues. In addition, given the specific emphasis on the 
role of agriculture, we also discuss the emerging economic studies analyzing how climate change affects agricultural outcomes from a quantitative point of view.

In the next Section, we start by reviewing the literature on the impact of climate change on agriculture. The aim is also to speculate about which methods might be more suited to empirically address the link between weather-driven agricultural changes and migration. Section 3 discusses the existing economic evidence on climate change and migration, focusing on both internal and international migration. Next, Section 4 surveys the literature that emphasizes the role of agriculture as important mechanism linking climate change to migration, distinguishing between micro and macro studies. Section 5 concludes.

\section{Economic Effects of Climate Change on Agriculture}

The idea that agriculture is one of the most important channels driving the relationship between climate change and migration is related to two simple considerations. First, agriculture is exposed to weather and climate shocks more than almost any other sector in the economy. Secondly, agriculture is the main source of income and employment in rural areas of developing countries, where most migrants come from.

Since, other things constant, economic models of migration, e.g., [15], emphasize origin-destination wage differentials as one of the crucial drivers of migration, the first step to assess the role of agriculture is to investigate how climate change may affect income-generating opportunities in agriculture. In addition, a further channel linking climate change to migration through agriculture has to do with the effect of climatic shocks on food (in-)security, namely, on the availability of, and access to, safe and healthy food.

In what follows we shall discuss the state of the debate about the different methods for studying the economic impact of climate change on agriculture, also with the aim to clarify which could be the best suited to assessing the link between climate change and migration.

There are three main approaches that are currently employed to quantify the economic impact of climate change on agriculture: agro-economic models, cross-sectional or Ricardian models, and time-series or panel data models (see Table 1) [16]. After outlining the main features of the first approach, we shall focus attention on the last two which, being based on econometric tools, are largely employed by economists and, to date, play the most important role in investigating the climate-migration relationship.

Table 1. Main characteristics of models quantifying the impact of climate change on agriculture.

\begin{tabular}{|c|c|c|c|c|c|c|}
\hline Methods & Structure & Data & Adaptation & $\mathrm{CO}_{2}$ Fertilization & Advantages & Disadvantages \\
\hline $\begin{array}{l}\text { Integrated } \\
\text { agro-economic } \\
\text { models }\end{array}$ & $\begin{array}{l}\text { A combination of } \\
\text { crop models with } \\
\text { farm/agricultural } \\
\text { economic models }\end{array}$ & $\begin{array}{l}\text { Field experiments, } \\
\text { economic data, and } \\
\text { behavioral } \\
\text { parameters }\end{array}$ & $\begin{array}{l}\text { Gradual } \\
\text { dynamic } \\
\text { adjustment to } \\
\text { climate change }\end{array}$ & $\begin{array}{l}\text { Included but not } \\
\text { without problems }\end{array}$ & Theory-based & $\begin{array}{l}\text { High } \\
\text { implementation } \\
\text { costs }\end{array}$ \\
\hline $\begin{array}{l}\text { Ricardian } \\
\text { models }\end{array}$ & $\begin{array}{l}\text { Statistical tools } \\
\text { based on } \\
\text { cross-sectional } \\
\text { data }\end{array}$ & $\begin{array}{l}\text { Land values or farm } \\
\text { profits and long-run } \\
\text { realizations of } \\
\text { weather, plus many } \\
\text { farm-level controls }\end{array}$ & $\begin{array}{l}\text { Long-run } \\
\text { adjustment to } \\
\text { climate change }\end{array}$ & $\mathrm{NO}$ & $\begin{array}{l}\text { Cost-benefit } \\
\text { analysis of } \\
\text { climate change }\end{array}$ & $\begin{array}{l}\text { Omitted } \\
\text { variable bias, } \\
\text { no global } \\
\text { models }\end{array}$ \\
\hline $\begin{array}{l}\text { Time-series } \\
\text { and panel } \\
\text { models }\end{array}$ & $\begin{array}{l}\text { Statistical tools } \\
\text { based on panel } \\
\text { data econometrics }\end{array}$ & $\begin{array}{l}\text { Crop yields and/or } \\
\text { farm profits, } \\
\text { seasonal/annual } \\
\text { realizations of } \\
\text { weather }\end{array}$ & $\begin{array}{l}\text { From short-run } \\
\text { to medium-run } \\
\text { adjustment to } \\
\text { weather change }\end{array}$ & $\mathrm{NO}$ & $\begin{array}{l}\text { Robust to } \\
\text { omitted } \\
\text { variables bias }\end{array}$ & $\begin{array}{l}\text { Potential bias } \\
\text { due to errors } \\
\text { in weather } \\
\text { variables }\end{array}$ \\
\hline
\end{tabular}

Source: based on [16].

\subsection{Agro-Economic Models}

Agro-economic models are a combination of both crop and economic models [17]. Crop models, also called biophysical models, are based on a set of parameters related to a particular crop capable of 
simulating its growth process, under different assumptions concerning both environmental realizations (e.g., temperature, precipitation, solar radiation, nutrients) and management practices (e.g., planting dates, fertilization levels). The outputs of several agronomic models, virtually one for each relevant crop or agricultural activity, are then integrated into a partial or general equilibrium model with a view to simulating the agricultural system $[18,19]$. The resulting Integrated Assessment Model (IAM) can be used to replicate farm economic behavior with the aim of estimating the changes in consumption, production, trade, and welfare, given some projection of future climate changes. Specifically, IAMs used for economic policy analysis are based on general equilibrium models, considering the overall economy, not just the agricultural sector. Typically, they include four broad components: "(1) a model predicting the growth of greenhouse gas (GHG) emissions; (2) a model mapping GHG emissions into climatic change; (3) a damage function that calculates the economic costs of climatic change; and (4) a social welfare function for aggregating damages over time and potentially across space" [20] (p. 783).

The key advantage of agro-economic models lies in their theoretical foundation: namely, both crop and economic models are firmly based on structural relationships derived from basic principles that explain how plants grow and how farmers (and consumers) react to price changes [21].

Despite these and other potential advantages of agro-economic models, such as the possibility of accounting for the effects of $\mathrm{CO}_{2}$ fertilization, there are also important drawbacks that need to be considered [22]. In particular, recent studies comparing agricultural productivity predictions from crop models with those produced by statistical econometric models show that they do not significantly differ from each other [21,23]. This result is relevant from a pragmatic point of view, as an average agro-economic publication normally involves several researchers, and thus has implementation costs significantly higher than those of a typical analysis based on the econometric approach. Clearly, the fact that this research approach is labor intensive is not in itself a drawback. In addition, in countries/regions where agricultural production is not driven primarily by market-oriented monoculture production, and/or in areas where farm revenue data are unreliable/unavailable, agro-economic models often represent the only reliable approach to investigate the impact of climate change.

At any rate, also because the literature investigating the nexus between climate change and migration is still in its infancy, it comes as no surprise that, to date, there should not be published papers based on integrated assessment models studying the climate-migration relationship. Indeed, at the best of our knowledge, the only working paper using an IAM to investigate the effect of climate change on migration is [24]. Here the authors account for both the agricultural channel and the temperature effects on labor productivity and health. Overall, they do not find strong economic-induced migration effects attributable to climate change, under a $2{ }^{\circ} \mathrm{C}$ global warming scenario. In addition, a recent report by the World Bank [6] represents perhaps the first-ever attempt to introduce climate impacts into a model of future population distribution, with the most important sectoral impacts on migration (see chapter 3). The model, applied to within-subregions migrations in South Asia, East Africa, and Central America (Mexico), underscores the potential for an increase in the number of climate migrants through 2050, highlighting climate out-migration from rain-fed cropping areas, and indicating that climate impacts on crop productivity in these subregions may potentially disproportionately affect farming households (see chapter 4).

\subsection{Cross-Sectional Models}

Moving to econometric models linking agricultural outcomes to weather variables, the main distinction must be drawn between cross-sectional studies and studies based on panel data methods. The former were the first to make their appearance in the literature. Yet, in recent times, panel data studies have become progressively more relevant [20].

The rationale underlying cross-sectional models is based on the Ricardian theory of land rent, where competition for land in the long-run makes land value correspond to land productivity [25]. Indeed, in a competitive land market the farmland value is the present value of future rents, under the 
standard assumption of profit maximizing farmers. By exploiting the spatial variation in land value and climatic conditions, cross-sectional models estimate the long-run relationship between land value and different climatic conditions. In addition, this method provides direct welfare measures of climate change impacts on farmers, because the dependent variable normally is a measure of landowners' or farmers' wealth or income, i.e., land value, rent, or farm profit [26].

The typical Ricardian model regresses cross-sectional information about land rents at the farm or territorial level (e.g., US counties or EU regions) on the long-run distribution of weather realizations (typically over 30 years), plus several other covariates. Given the long-run perspective of this modeling structure, the general idea is that the estimated relationship incorporates also the farmers' adaptation to climate change. This is an important feature of the cross-sectional approach that, ideally, represents one of its chief strengths. However, there are also critical weaknesses, such as an omitted variable bias, as well as the distortionary effect of the poor functioning of land markets, which is particularly severe, especially in developing countries [27]. It is important to notice that a proper working of land markets is a key assumption of the Ricardian approach. However, in many developing countries, where land rights are less than perfectly assigned, land markets are far from the ideal perfectly competitive model, making the application of the Ricardian approach less reliable [28].

The first empirical application of a Ricardian model to estimate the economic effect of climate change on US agriculture can be found in [25]. These authors have shown that, overall, global-warming appears to have had a very low impact on US agriculture. Different conclusions are reported by [29], where the authors include climatic variables different from those employed in previous studies: namely, they use degree days, defined as the sum of the days when the daily average temperature is above (or below) a certain threshold, during the growing season. Contrary to the results obtained by [25], their findings show that for the US counties considered the aggregate impact in the near-to-medium-term is a 10 to 25 percent decrease in aggregate land value, depending on the climate scenario chosen.

Since the seminal contribution provided by [25], cross-sectional Ricardian studies of climate impact on agriculture have been carried out for more than 40 countries [26]. The emerging results are clearly strongly related to the weather and climatic conditions prevailing in the countries considered. For example, a marginal increase in temperature may be beneficial in cold regions, but harmful in tropical ones. Similarly, the effect of precipitation tends to be positive in dry regions and negative in wet ones. Given this variability, when we consider the aggregate effect at the global level, the combined impact of temperature and precipitation tends to vanish in the short-run. However, since the effect of weather variables on agricultural outcomes is non-linear, as pointed out by [29,30], an increase in temperature due to global warming will become more and more negative and problematic in the medium- to long-run. As an example, considering areas and continents from which current migration mainly comes (i.e., Asia, Africa, and South America), the economic predictions derived from Ricardian models under mild $\left(2{ }^{\circ} \mathrm{C}\right)$ and more severe $\left(4^{\circ} \mathrm{C}\right)$ temperature increase scenarios suggest an overall farm net revenue reduction going from -8 to $-30 \%$, respectively [26] (Table 1).

\subsection{Panel Data Models}

A significant step forward in the climate econometrics literature starts with the methodological contribution provided by [27]. By exploiting the within time variation, they find out whether agricultural profits in US counties respond to random fluctuations in weather. This new approach based on panel data methods has several interesting features for assessing the impact of weather on agriculture and other economic outcomes.

The key advantage of the panel data approach lies in the possibility to include fixed effects in the model specification [31], allowing the researcher to control for any confounding factor that is time-invariant within each unit of observation. For example, many farm or local characteristics of agricultural activities that strongly affect production outcomes, such as soil quality and management ability, are simply not observable in most datasets; hence fixed effects can fully account for them. In addition, using a fixed-effect model is equivalent to take the deviation from the respective mean 
of each considered variable. This is relevant for weather variables because the deviations from their respective means, i.e., weather shocks, tend to be random, and therefore exogenous with respect to the choice of farm inputs [32,33]. Hence, the omission of these inputs will not affect the estimated parameters on weather variables. It should be noted that things change when weather variables are introduced non-linearly. This is because both deviations from the mean and the mean itself enter the identification. Indeed, as highlighted by [34], the square of the demeaned variable is different from the demeaned square variable. In addition, at least in principle, panel data models can exploit the possibility to include also time fixed effects, a simple strategy to absorb any factor common to all farmers or regions exposed to the same external shock, such as a variation in the level of prices, the introduction of a government policy measure or any other macro-shock.

The relationship between weather variables (temperature and precipitation) and economic development, both in levels and in growth rates, has been analyzed by means of panel data methods in [35] and [36,37], where the authors found that the relationship between income and weather is significantly negative only in developing countries. It may be interesting to note that this relationship appears to be mainly driven by the negative effect of warming on agricultural output: an increase of $1{ }^{\circ} \mathrm{C}$ in average annual temperature translates to a 2.6 percentage point decrease in agricultural output. This is important because it suggests that the impact of climate on agriculture may vary according to the country income level [38]. However, with the help of a slightly different methodology, the effect of warming on GDP per-capita growth, as well as on agricultural value-added growth, has been found in [39] to be non-linear (i.e., inverted U-shaped) and, interestingly, very similar in both poor and rich countries. This clearly has important implications when studying the projections under different global warming scenarios, because the detected non-linearity translates to more severe economic damages, both when we consider agriculture and the overall economy.

Many panel data studies applied to developing countries confirm the above relationship. Important negative effects of higher temperature on the yield of the main cultivated crops, ranging from -3 to $-22 \%$ in the most affected developing countries and crops, are reported by [40], for Sub-Saharan Africa (SSA), and by [41], at the global level. These results strongly predict that climate change could affect income-generating opportunities in agriculture, one of the main drivers of people's decisions to move.

However, the panel data approach has limitations, too. On this, the interested reader may refer to the recent review provided by [32]. Below we discuss only two major drawbacks of this approach that, in our view, are crucial in understanding the relationship between weather-induced agricultural shocks and migration, namely, the likely occurrence of measurement errors and these models' limited ability to account for farmers' adaptation.

Starting from measurement errors, it is well-known that one shortcoming of panel data fixed-effect models is that a large share of cross-sectional variation is absorbed by individual effects. Thus, if the variation of the key variable of interest, say temperature, displays a small within time variation, as it is indeed the case, then the presence of measurement errors in weather data could induce an attenuation effect, biasing the estimated coefficient towards zero. This is the classical problem of weather data coming from discretely distributed weather stations, but normally interpolated to retrieve information at a finer scale resolution. In fact, the quality and the presence of weather stations tend to be correlated with the level of country development. Hence, global analyses and studies on low-income countries will be more affected by the attenuation bias. This represents one of the identification challenges in studies aimed at identifying the weather-induced agricultural effects on migration, as most emigrants do indeed come from low- or middle-income countries [42].

The second big challenge facing panel data studies is their ability to capture farmers' adaptation, especially in the long-run. As a matter of fact, studies that exploit yearly variations in weather tend to capture only limited adaptations as short-run weather changes tend to be unexpected by farmers that consequently have few possibilities to adjust their choices [26]. 
More recently, with the aim of capturing adaptation, some papers have introduced the so-called long-difference approach, exploiting a mixture between the cross-sectional and the time-series identification strategies [20,43]. The general idea is based on the fact that, since changes in climate are gradual, averaging across long time-spans should offer the possibility to pick up both direct and belief effects (i.e., adaptation) of climate change, because people only adjust their beliefs when environmental changes are expected to be persistent [32]. However, studies comparing climate-change effects with short- and long-run data frequency have often found that the magnitude of the estimated impacts of climate change on agricultural productivity are not so different [20,43]. These results, implying no or little adaptation effects in agriculture, are compatible with two different interpretations. First, adaptation alternatives may be scarce to farmers, which is called "adaptation illusion" [44], perhaps a plausible interpretation with reference to several developing countries. Secondly, the yearly variation in weather variables suffers from large measurement errors biasing the coefficient toward zero [39].

Some authors have raised further concerns about the possibility to identify adaptation through panel data econometrics [45]. The main point is that regressing agricultural outcomes on current weather realizations totally disregards the so-called belief effect, namely the change in farmers adaptation decisions (dates of plantation, crop varieties, and so on) induced by expectations about future weather. The last issue has been recently addressed by [46], where the author models forward-looking adaptation: namely, to capture expectations about future weather, he includes in the empirical model not only realized weather but also public forecasts of El Nino/Southern Oscillation (ENSO). An alternative approach that should incorporate adaptation, still based on panel-data, has recently been proposed by [47]. In short, by exploiting one well-known property of the envelope and gradient theorems, the authors have argued that it is possible to estimate the long-run income responses to climate by using the short-run income responses to weather, if there are sufficiently large panels of similar economies that span the space of possible climates. In an application to US counties, the authors have shown that, by incorporating adaptation, the magnitude of the estimated future economic effects increases rather than decreasing. This is because the economic effects of the future increases in temperature, which are larger for cooler and less adapted northern counties, are positively correlated across space with the distribution of economic activity. Thus, models that assume uniform marginal effects tend to under-estimate total future losses, rather than over-estimating them.

\subsection{Implications}

From the above discussion we can draw some interesting insights about the potential role played by the agricultural channel in mediating the relationship between climate change and migration. First, income is one of the factors motivating individuals or families to migrate. Hence, the strong (negative) economic effects of climate change on agriculture, predicted by the current empirical literature, may suggest that climate change could exert a significant impact on human mobility via the induced impact on agricultural income. It should be noted that the income effect on migration might act either way. It acts in a positive direction when potential migrants expect a positive income differential to exist between destination and origin locations. However, it curbs migration when a low income level in the origin location acts as a liquidity constraint on potential migrants, as embarking upon a migration process requires the availability of major financial resources.

Secondly, considering the use of agro-economic models to investigate the relationship between climate change and migration, it is important to emphasize that such models characteristically rely on econometric estimates of specific behavioral parameters, such as the (agricultural) income elasticity of migration induced by weather changes, whose selection often significantly affects the outcome. In IAMs, this is usually summarized by a so-called "climate damage function", specifying how temperatures or other climatic variables affect economic activities, such as agricultural production and food consumption [20]. In other words, it is important to emphasize that to estimate the impact of weather-driven agricultural shocks on migration exploiting an agro-economic model, we still need to know some (statistically estimated) parameters, linking people mobility to climate change. Thus, 
developing transparent and credible identification procedures from reduced-form econometric models should be viewed as an important bridge between more structural and reduced-form methods $[20,48]$.

Thirdly, an interesting point is to speculate on whether Ricardian models or panel data models provide the most suitable econometric approach for investigating the nexus between weather-induced agricultural shocks and migration. In general terms, it is difficult to argue that one approach is better than the other: indeed, they are similar to tools in a toolkit to be used as appropriate. However, as discussed above, panel data methods have several desirable properties that apparently are not shared by cross-sectional approaches. A further consideration might be the following: since migration induced by climate-driven agricultural shocks is largely viewed as a strategy aimed at coping with climate changes, relying on a cross-sectional approach that fully incorporates adaptation is probably not the best empirical way of proceeding. In fact, the use of a Ricardian approach makes one run the risk of double-counting adaptation through migration, ceteris paribus. Finally, as we have seen, Ricardian models are more demanding than panel data models in terms of agricultural and geographical control variables. Hence, it is hard to imagine that the former models can be employed to analyze the relationship between climate change and migration at the global level. Yet, it should be clear that only future studies will eventually clarify this issue.

\section{Migration as a Coping Strategy}

Climate change is currently considered one of the most relevant issues at both an economic and a socio-political level. Consequently, human migration induced by environmental factors might become a complex social outcome of great concern for both origin and destination countries. A growing number of research works have been investigating the consequences on migration of short-, medium-, and long-term climate variability using different econometric approaches [49]. Several conflicting results can be found in the literature highlighting how climate-induced migration is a complex phenomenon, which depends on a variety of specific socio-economic conditions [50].

Migration, as an adaptation strategy to climate change, presents both opportunities and challenges [11]. On the one hand, migration could enhance the capacity of households to cope with climate change, for example through the contribution of remittances, or it can be viewed as a way to diversify income sources. In these cases, migration can mitigate the negative impact of climate change. On the other end, migration could also exacerbate vulnerability to climate risks, for example when it increases the pressure on (scarce) natural resources.

To clarify the link between climate change and migration, one should take the following two steps: first, one should classify climate variations, sharply distinguishing short- from long-term changes; secondly, one should classify types of migrants, precisely separating at least internal from international migrants. We are aware that a more complete characterization of migrants should also consider other dimensions, such as the timing and duration (temporary vs permanent) of their migration decisions, and their characteristics, e.g., gender, age, education, skills. However, our key interest here is the distinction between those moving within the same country (internal migration) and those embarking upon a costly migration process, which implies crossing one or more borders (international migration) [51].

Climatic variations are normally defined with respect to the duration of their realization. We consider natural disasters as short-term climatic shocks, since they occur at a specific point in time, and individuals are not aware of the timing of their realization. Climate variations, such as global warming, instead, are generally viewed as long-term shocks. Even if the data concerning these variations can be collected daily, how individuals adapt to such changes is a matter of long-run decision processes.

Whether to migrate internally or internationally depends first on migration costs, and secondly on the nature of climatic shocks. Individuals may prefer to embark upon an internal migration process since they experience too high liquidity constraints. Or it can also be the case that internal migrants are mainly affected by natural disasters, so that they do not have time to prepare themselves to migrate 
internationally, and they only want to run away from bad environmental situations. However, some works support the idea that natural disasters may have an impact on international mobility, too [52-54]. More generally, environmental migrants are, most of the time, people affected by long-term and permanent climate variations in temperature and precipitations; hence, they consider the migration process as a long-run adaptation strategy.

Instead of looking at internal and international migration patterns as if they were two distinct phenomena, there are also studies that claim a direct connection between internal (mainly from rural to urban areas) and international migration [55]. The main argument is that rural populations affected by climate shocks first move into cities, raising urbanization rates and exacerbating social-economics conditions. Then, some of them may positively evaluate migration abroad to improve their economic condition due to an increasing pressure on wage rates because of the higher number of individuals in search of a job [49].

\subsection{Climate Shocks and Internal Migration}

Internal migration can be defined as a series of individual or household movements within the country, either from one rural area to another, or from rural to urban areas, or from one province to another of the same country. While the economic return originating from this kind of migration is normally lower than that associated with international migration, such a move is clearly less costly than the alternative one. In addition, it is also linked to the structural adjustment usually taking place during the process of economic development [56].

The literature on climate shocks and internal migration presents different results depending on both the variables and indicators employed to measure climate change and the econometric strategy adopted. Most papers focus on precipitations and (extended) droughts as climatic factors affecting migration, especially of more vulnerable farmers. Yet, a relatively small but increasing number of papers stress the key role played by temperature shocks with respect to precipitation anomalies. Studies using panel data methods, especially when applied to different contexts in a comparable manner, show how complex the relationship is between climate change and migration, where non-linearities and threshold effects often dominate.

Most of the literature discussing internal migration highlights that a reduction in precipitations may cause an increase in urban migration, for example in sub-Saharan Africa [57], or, more generally, an increase in internal migration, as in the cases of Mali, Burkina Faso, and Tanzania, respectively analyzed by [58-60]. As underlined by [61], the most frequent migration pattern is that occurring between rural areas. In fact, the lack of information available to people coming from rural areas and the limited opportunities, in terms of labor market prospects open to them, may prevent such people from moving internally to urban areas or internationally $[58,59,62]$. How the amount of available information affects internal migration patterns in Indonesia is an issue tackled by [63].

Also, a period of extended droughts, which causes a deterioration of soil quality, has been shown to promote internal migration [64]. To overcome the negative impact of climate change on agriculture, individuals are forced to move to other districts or regions not affected by the same negative weather event. The paper also highlights that those people who are mostly affected by extended droughts are the more vulnerable farmers, i.e., those working on sandier soils. However, looking at a specific climate change measure such as precipitation, several studies find no significant effect on internal migration. No effect on within- or across-village migration is found in [65], where the case of Pakistan is analyzed. According to [66], rainfall does not affect the migration propensity of people living in agricultural communities in Ghana, even if their household economy depends on agriculture.

Only few micro-level studies on the effect of temperature on internal migration can be found in the literature. A further rise in baseline temperature in the US Corn Belt has been shown to raise internal migration due to its effect on crop yields [67]. Inter-provincial migration of households due to temperature anomalies was observed in Indonesia [68] and, for male migrants, in the case of Pakistan [65]. Furthermore, in a study concerning the US [69], as well as in other studies at the 
micro-level, climate shocks, as captured by measures of temperature, humidity, and wind, have been shown to result in short-distance internal migration [52,60,70,71].

In [54], the authors point out that internal migration is generally due to rural-urban displacement and find a mixed evidence of climatic influence on human mobility depending on the nature of the shock. To measure internal migration, they use data on urbanization rates from the World Urbanization Prospects [72]. As shown by [53], natural disasters may increase the rate of urbanization in developing countries, while an increase in temperature positively affects internal migration in middle-income, but not in low-income countries, as liquidity constraints hinder migration.

Similar results can be found in [73]. Starting from the baseline assumption that migration can be considered a risk-coping strategy to climatic shocks, they find that in rural Tanzania a $1 \%$ reduction in agricultural income induced by weather shocks increases the probability of migration by 13 percentage points, on average, within the following year. Similar results can also be found in [57].

A recent work analyzes migration patterns due to climate change from rural to urban areas in six countries of South America [74]. The paper employs a common analytic approach and uniform definitions of migration and climatic shocks. Its main findings show that monthly temperature shocks have the most relevant effects on migration decisions, compared with rainfall shocks and gradual climate change. Overall, the authors find an increase in the propensity to migrate from rural to urban areas in the case of both positive and negative temperature shocks, stressing a higher probability in the second case. Notably, they find evidence of heterogeneity across demographic groups and countries, highlighting the complexity of the nexus between climate change and migration and rejecting any simplistic interpretation of the analyzed phenomena.

The effect of weather variations on migration between provinces in the Philippines, a country that has experienced a mass internal migration and a high incidence of weather variability and typhoons, is investigated in [75]. The authors use a panel data derived from the Integrated Public Use Microdata Series (IPUMS) to account for migrants. Their results indicate that an increase in temperature has a negative effect on annual rice yields, hence promoting internal migration. However, they find no clear evidence of any effect of precipitation on migration [76]. Here the link between weather variations and human mobility acts through a variation in agricultural productivity; in Section 4 we will examine this link in greater detail.

Still at the province level, as reported by [68], it appears that household permanent migration in Indonesia, a country highly dependent on agriculture, is influenced by weather fluctuations, more than by unexpected natural disasters. Using a 15 years panel dataset on 7185 households, they analyze permanent and province-to-province migration, finding a non-linear effect of temperature on migration. Specifically, a rise in temperature above $25^{\circ} \mathrm{C}$ turns out to be related to an increase in emigration through its impact on economic conditions. However, they do not test directly the extent to which agricultural or non-agricultural outcomes are at the root of the weather-induced migration relationship.

\subsection{Climate Change and International Migration}

Looking at international migration, the level of the analysis, i.e., micro vs. macro, often matters. Indeed, one shortcoming of the current literature investigating climate change and international migration is related to the small number of (longitudinal) macro-studies about the effect of weather shocks on international migration, which makes it problematic to generalize the existing micro-evidence.

A systematic review on the empirical findings obtained by studies investigating the international migration dimension of climate change can be found in [50]. Here the authors call attention to the important role played by the specific context under scrutiny in shaping environmental migration at the international level. Moreover, they emphasize the importance of the complex dynamic interactions between environmental and non-environmental factors in explaining international migration-a conclusion very similar to the one previously reached in analyzing internal migration. 
In what follows we focus the attention mainly on more recent macro-studies only partially covered by [50]. These studies are also the result of a few recent efforts made in building comprehensive datasets, such as the bilateral migration dataset of [77]. Using these data, a new wave of macro-studies has started to investigate the impact of climate change on international migration [53,54,78-80]. Broadly speaking, the main findings appear to confirm the previous micro-evidence, but they also raise new issues. Indeed, when one focuses attention on the mechanisms driving the results, the empirical evidence is scarce. This is an important shortcoming of the current literature, especially because there exists a growing evidence showing that the effect of climate change on international migration tends to be mainly indirect [53,73].

Several papers, among which $[53,78,79]$, try to estimate the climate-migration link using a gravity-like model. As it is well-known from the international trade literature, the gravity equation represents one of the most successful models in economics. Empirically, it explains bilateral trade flows between any two countries through their respective economic sizes (i.e., GDPs) and their bilateral trade costs, after accounting for the so-called multilateral resistance indices [81].

The first paper to study the impact of long-term climate variations and natural disasters on international migration using bilateral migration data is [53]. Migration seems to depend upon a given country's agricultural share of GDP $[8,80]$. However, these papers show indirect effects of environmental factors on international migration, particularly through their effect on wages. This result is interesting because it is suggestive of an econometric strategy that uses weather variables as instruments for wage differentials.

Bilateral migration flows from 142 countries into 19 OECD countries are studied in [78], where a positive and significant correlation is found between weather variations and human migration. The same macroeconomic approach is followed by [79]. Here the authors consider type, size, sign, and seasonal effects of climatic shocks, also paying specific attention to expectations, since they can control for the yearly variation in migration by exploiting OECD data (1990-2001). One shortcoming is that they can account only for emigrants to OECD countries, thereby drastically limiting their analysis, as a huge number of migrants move to neighboring developing countries. However, their results are in line with other empirical papers, where the incidence of adverse climatic events in the countries of origin has a significant direct and indirect effect on out-migration from poor to rich countries, especially from areas with large agricultural sectors.

It is important to highlight that all the papers using a gravity-like approach that have been discussed above incorporate only positive migration flows in their bilateral migration equations. This is an important drawback, because ignoring nil migration flows in the dataset implies omitting important pieces of information, which could bias the estimated parameters-a well-known problem in the international trade literature. Therefore, an important task for future research would be to extend the insights from this literature in such a way as to build a generalized gravity framework, capable of explaining migration phenomena by considering also zero-migration flows.

\section{Climate, Agriculture and Migration}

Climate effects on migration have been most commonly assumed to occur via an agricultural channel in areas mainly dependent on agriculture [73,82]. In such a context, climate changes have been framed as first affecting agricultural production and then acting on individual and household migration behavior through related effects on livelihoods $[65,83]$. The importance of agriculture as a mediating channel in the relationship between climate change and migration emerges clearly from both the micro-level country studies and the relatively few macro-level analyses using cross-sectional data over longer time periods. However, the relationship is complex, often country-specific, and possibly acting in either direction: namely, negative agricultural income shocks induced by climate variability can not only trigger migration responses, but also hinder them. In addition, it is not yet clear whether such migration responses are direct, i.e., working through income effects, or indirect, i.e., based on more complex mechanisms involving, for example, factor and/or output conflicts [84]. 
From both micro- and, especially, macro-studies, it emerges that temperature shocks, vis-à-vis rainfall shocks, normally exert a more relevant effect on migration through the agricultural channel. Moreover, in the current literature, especially due to data limitations, only few macro-studies are available, most of which do not adopt a "structural" estimation approach capable to identify true causal relationships. Finally, a major shortcoming of the existing literature is the lack of studies explicitly focusing on food security, a complex dimension largely missing in the current debates on climate change and migration.

\subsection{Micro-Studies at the Individual and Household Level}

Rural individuals or households may embark on internal or international migration to ensure against weather variations and to cope with risks associated to agricultural (income and productivity) variations since, as outlined in Section 2, at high temperatures and extremely low or high precipitation levels the overall profitability of agriculture declines [25,85].

Micro-level studies using individual and household data, and employing both cross-sectional and panel data approaches, have been often applied to countries highly dependent on the agricultural sector as the main source of income, such as Ecuador [86,87], Nigeria [76,88], Bangladesh and Ethiopia [53,83,89], Indonesia [68,90], and Tanzania [73].

Considering migration as a household decision, [88] uses two different surveys on Nigeria (2010-2011) and Ghana (2005-2006). Defining a migrant household as one that receives remittances and controlling for regional fixed effects, the authors find a (statistically weak) inverted U-shaped relationship between both temperature in the dry season and precipitations in the wet seasons and the propensity to migrate in farm households. On the contrary, in the sample of non-farm households no significant impact of climate on migration can be detected.

A similar issue is also tackled by [76]. Here the authors, focusing on Nigeria and using degree-days to account for income variability, find that, in north Nigeria, households with both ex-ante and ex-post higher risk participate in the migration process to a larger extent. The most robust finding of the paper is related to the ex-post risk effect on migration for males, probably due to the presence of gender differences in the return to labor at the household level with respect to the destination labor market. Similar gender differences in migration response to weather shocks are reported by [52] for Ethiopia. It should be noted, however, that, in the paper on Nigeria [76], the authors do not test directly the structural relationship between the impact of weather-induced risk on household farm income variability, on the one hand, and its eventual migration effect, on the other.

The importance of international migration as a response to agricultural shocks is emphasized by $[86,87]$. A first important aspect of this research lies in the availability of micro-level data on emigrants, defined as individuals who have parted from the origin household for at least six months in the year considered. The second original aspect of the paper lies in the use of six environmental measures (irrigation on farm, mean annual rainfall, mean rainfall seasonality, yearly rainfall deviation, land quality index, and topographic slope). Through a multivariate model and accounting for various covariates, they study different forms of migration, such as local, internal, and international migration. Their results indicate that adverse environmental conditions do not consistently increase rural emigration, while, in some cases, they even reduce it. On the contrary, households respond to climate change in different ways, giving rise to complex migratory responses.

In the wake of [91], attention is exclusively focused on precipitations in [89], too. They assess ex-ante and ex-post impacts of rainfall in rural Ethiopia, using rainfall variability in the first case, while employing the prevalence of negative rainfall shocks between one and two standard deviations around the long-run mean, as a determinant of ex-post decisions. Accounting for agricultural income as a plausible driver in the migration process, they apply a random effect probit model to estimate the rural household migration decision in response to weather variability. Results are still robust when applying an IV probit regression. 
Data on internal and international migration in 2004-2009 period from 9812 origin households, in Kenya, Uganda, Nigeria, Burkina Faso, and Senegal, have been analyzed at the district-level by [49]. By means of a negative binomial regression model, the authors show that climate change has country-specific effects on migration. On the one hand, an increase in precipitation has no impact on migration across countries. On the other, an increase in temperature might cause an increase in emigration in Uganda, while the opposite effect holds true in Kenya and Burkina Faso and no effect takes place in Nigeria and Senegal. Their results support both the hypothesis of climate-induced migration, with a stronger effect of temperature variability on internal than on international migration, and the idea that migration can be considered as a household investment strategy to overcome negative income variations. However, the shortcoming of this work is that it exploits too many contextual features to explain climate effects, so that its results appear to be mostly driven by the selection of the data and the choice of the time periods of the analysis.

In a study referring to Pakistan [65], the authors use a longitudinal panel survey (1991-2012) to look at the relationship between weather variations and long-term migration. They examine the effect of climate changes on annual income for farmers and non-farmers during the 1986-1991 period, finding negative agricultural income variations when temperatures are extremely hot, while flood has almost no significant impact on migration.

In a more recent paper [92], the authors use district-level data from Bangladesh to study how the changes in climatic variables impact migration through agriculture. Taking the advantages of three inter-census periods (1974-1980, 1981-1990 and 1991-2000), they apply both a fixed effect (FE) and an Instrumental Variable (IV) methodology showing that uncertainty about temperature and rainfall have an impact on agricultural productivity and hence on migration behavior.

Considering South Africa, [93] investigates climate variability and internal migration using two waves of census, covering the years 1997-2001 and 2007-2011, respectively. Adopting a gravity-like approach, they find that positive temperature shocks, as well as positive and negative excess rainfall at the origin, increase migration. However, they also show that this effect is conditional on migrants' characteristics. Specifically, while black poor migrants appear to be strongly affected by weather variability, white and higher income migrants do not. They also provide direct and indirect support to the idea that the agricultural sector works as a transmission channel through which climatic shocks induce migration. From this perspective, the authors can show that changes in agricultural employment, predicted by weather variability, turn out to be a significant predictor in the migration equation.

An important shortcoming of the current literature is the almost total lack of studies focusing on climate-induced changes in food security and migration. As discussed by [94], a possible explanation is that current empirical analyses linking migration and food security prioritize the interplay between these two dimensions almost exclusively from a rural household perspective [95]. Yet, such rural perspective might be misleading, because in many developing countries, notably in Africa, the rural-urban dichotomy has progressively lost its weight. In such a context, often remittances appear to play an important role to mitigate food security issues in rural areas. Consequently, food insecurity often tends to become a growing concern more for urban areas than for rural ones [94].

\subsection{Macro-Studies at the Country Level}

To date, there are few empirical contributions at the macro-level studying the extent to which agriculture is an important mediating channel in the relationship between climate change and international migration. In one sense this is problematic, because, on the one hand, the rich evidence at the micro-level summarized above is often relatively narrow in geographic scope, and, on the other, different micro-studies are often based on diverse methodologies, which it is difficult to put together. As a result, the extent to which the previous findings can be generalized across populations and contexts clearly is an important open question. 
Macro-studies can be distinguished between those based on gravity-like (bilateral) migration equations, as in [10,80], and those exploiting panel data econometrics, as in [54,96].

Let us take up the gravity-like approach first. An important contribution that carefully investigates the nexus between climate change, agriculture, and migration, is provided by [10]. Starting from the consideration that little is known about the mechanisms through which climate change affects migration, the authors exploit a large bilateral migration dataset to estimate a gravity migration equation. In particular, they use bilateral annual data over the period 1980-2010 covering 163 origin countries and 42 destination (largely OECD) countries, controlling for country-pair fixed effects. To identify the possible role of the agricultural channel, they use several agriculture-related variables, such as grain yields and the share of agricultural value added in GDP. Their main results are in line with the large evidence documenting a positive and statistically significant relationship between temperature and international migration, but only in the most agriculturally oriented countries. Quantitatively, considering the top $25 \%$ agricultural countries, an increase by $1{ }^{\circ} \mathrm{C}$ in temperature implies a 5 percent increase in emigration. It should be noted, however, that, though the authors provide much indirect evidence on the importance played by the agricultural channel, they also recognize that " $[. .$. ] none of these results individually prove that agriculture is the main channel behind the temperature-migration relationship [ ... ]" [10] (p. 142). The reason for this disclaimer is that their paper does not attempt any "structural" estimate of the way in which weather affects agriculture, hence migration, but confines itself to establishing robust, though only indirect, associations between such phenomena. To put it differently, showing that outmigration is more sensitive to higher temperature in countries with large agricultural sectors is significantly different from estimating the causal chain, if any, between weather-induced agricultural shocks and migration.

An attempt to go one step forward is made by [79], where a similar gravity approach is exploited, with a two-stage least-square (2SLS) research design. In the first stage, the authors model the determinants of the agricultural share in GDP using, among other things, climate variables (temperature and precipitation). In the second stage, by using a gravity model, they find a significant negative correlation between the predicted agricultural share of the origin countries and migration flows. In other words, when the agricultural share goes down, because of climate shocks, an increase in migration outflows is detected. The authors argue that, while it is difficult to find a direct effect of climate variability on migration flows, as shown by [53], climate anomalies spur international migration by reducing the agricultural share in the economy. However, one shortcoming of the analysis carried out in this paper is that, by using the agricultural share in GDP as a mediating variable, one can hardly explain whether the effect of climate change works specifically through the agricultural channel or, more generally, through its impact on the overall economic condition of the country, as pointed out by [37]. In addition, the 2SLS gravity specification is quite far from the standards that are normally adopted in the trade literature.

An important contribution is provided by [54]. Using data from 115 countries between 1960 and 2000, the authors put forward a panel data analysis to test predictions derived from an extension of the migration decision model originally proposed by [15]. The model assumption is that in poor and middle-income countries income is more significantly affected by weather variability as it largely depends on the agricultural sector. They find a positive impact of warming trends on the probability to emigrate in middle-income countries, while in poor countries a negative pattern emerges due to liquidity constraints. That weather-induced migration is particularly robust in countries where the agricultural share in value added is more important is shown in both [10,54]. Their contribution is relevant from a conceptual point of view because in their model the empirical specification is well-motivated by theoretical underpinnings. However, also in this case, the authors are unable to identify the causal chain on migration through agricultural shocks induced by climate change.

To the best of our knowledge, there are three main contributions that "structurally" investigate whether there exists a causal link between weather-induced agricultural shocks and migration. The first contribution, to be found in [96], focuses on the emigration from Mexico to the US in the 1995-2000 
and 2000-2005 periods. The authors identify the causal effect exploiting a 2SLS approach and using weather variables as instruments for crop yields in a panel data context with state fixed effects. In the first stage, they regress crop yields on weather variables (i.e., temperature and precipitation and their squares). In the second stage, the predicted crop yields are used to explain outmigration from Mexican States towards the US. The authors argue that this method allows one to identify the relationship between crop yields and migration without explicitly controlling for other confounding factors [96]. This statement is correct if weather variables are a true source of exogenous variation in crop yields or, to put it differently, if they represent valid instruments. However, if weather shocks affect migration also through other channels, e.g., through non-agricultural income, then non-controlling for these additional factors could bias the results. Their main findings show that a $10 \%$ reduction in corn yields would increase the fraction of the population immigrating to the US by about 2 percentage points.

In principle, the approach used by [96] is econometrically valid for estimating the causal effect of crop yields on outmigration. However, some important qualifications have been made by [97]. First, the authors of this paper have shown that, due to the neglect of time fixed effects in [96], many common factors potentially confounding the true effect, such as the NAFTA, the Peso crisis, etc., are not controlled for in the proposed specification. Second, and more importantly, by replicating the results obtained in [96], they have shown that, when time effects are controlled for, the statistical evidence of a causal relationship between weather-driven yield shocks and emigration disappears, which casts doubts on the fact that a truly causal effect may have been picked up.

The second contribution, provided by [67], applies a similar 2SLS econometric approach to the US internal migration in the period 1970-2009. As in the previous literature [30], the authors find an inverse relationship between temperature and yields, which leads to a population reduction through internal migration. This effect holds true only inside the Corn Belt counties, but not outside them, suggesting that it is driven by a change in agricultural productivity. Quantitatively, a $1 \%$ decrease in agricultural yields is shown to lead to an increase of $0.3-0.4$ percentage points in the net migration rate in rural counties of the Corn Belt. However, in the same way as in [96], also in this case the authors do not control for time fixed effects, on the ground that they would absorb too much of the (little) weather variability necessary to pick up the relevant effect (this is because they are forced to work with a dataset based on 5-year intervals, as migration information is only available from US Population Censuses with this time frame). Although the authors report many convincing robustness checks, one cannot be confident that unobserved common factors, such as changes in the US farm policy, rather than yield shocks, should not be held responsible for changes in emigration rates.

Previous studies are extended in two main directions by [42]. In the first place, the authors merge the macro-studies at the country level with the "structural" estimation approach proposed by [96]. This is important because single country evidence cannot be easily generalized. In the second place, they build a specific research design exploiting the extension, implemented by [54], of the migration model originally put forward by [15]. They conjecture that weather shocks may negatively affect the income levels of developing countries, but not those of the "rich" ones, because of the major role played by agriculture in developing countries. Given this assumption, they regress long-run emigration on agricultural productivity, instrumented by long-run weather shocks. In view of their conjecture, they run separate regressions for "poor" and "rich" countries, respectively, using the last as a counterfactual scenario. Considering a large data set of more than 150 countries observed over the 1960-2010 time span, and controlling for both country and year fixed effects, they provide support to the idea that negative shocks in agricultural productivity, induced especially by (long-run) increases in temperature, positively affect net migration outflows. This effect is relevant in middle- and lower-income countries, where technological adaptation is not possible, and migration may be treated as a plausible coping strategy [85], but not for "rich" countries. In addition to this, and consistently with the hypothesis of liquidity constraints trapping the most vulnerable population in place, the relationship between weather-induced agricultural changes and migration appears to be reversed (albeit insignificantly) for African countries, by far the poorest in the sample considered in the paper. From a quantitative 
point of view, they show that the magnitude of the impact of weather-induced agricultural shocks on migration increases by about three times, in passing from an OLS to a 2SLS model, where a $1 \%$ reduction in agricultural productivity leads to an increase in the outmigration rate of about $2 \%$, thereby producing a relevant economic effect.

Finally, using a reduced-form approach, a robust non-linear relationship between asylum applications in Europe and temperature fluctuations has been recently detected by [98]. In particular, the authors show that both cooler and (especially) warmer periods-with temperatures respectively lower or higher than $21-22{ }^{\circ} \mathrm{C}$-are associated with a significant increase in asylum applications by people from developing countries. The authors also investigate some possible channels behind this relationship, showing that the link is robust only when temperatures are measured during the relevant growing seasons in the origin countries, highlighting the important role played by the agricultural sector. In addition, they also show that the acceptance of the asylum applications by the host countries increases in magnitude two years after the applications have been filed, suggesting that host countries classify these migrants as refugees hit by conflicts and persecution, rather than as economic migrants. Quite surprisingly, however, when the authors control also for conflicts in the main equation, their estimated effects on migration turn out to be positive and significant, as expected, but the temperature effect is in no way affected. These results clearly underline the complexity of the chain leading people to migrate as an effect of weather shocks.

\section{Conclusions}

Our selective survey on classical economics-based researches on climate change, agriculture, and migration suggests that, overall, the empirical evidence supports the idea that climate-driven changes in agricultural productivity could represent an important mediating channel in the climate-migration relationship. In fact, the importance of agriculture emerges from both plenty of micro-level country studies based on individual or household data and the few macro-level analyses using cross-sectional country data over longer time periods. Thus, policy actions targeted to sustainable agriculture and rural development can both help tackle the challenges posed by climate change and create opportunities in the face of growing internal and international migration.

Said that, it is also important to stress that much of the current evidence is based on statistical associations that have nothing to do with causal inferences. Indeed, only a few studies try to investigate the structural relationship linking climate change to changes in agricultural productivity and incomes, and then to migration. This is an important shortcoming of the existing literature, which calls for the use of a more structural approach and more sophisticated research designs, enabling the researchers to better discriminate among different mechanisms concurrently at work in the economy or in society. Indeed, finding agricultural variables directly or indirectly associated with migration responses does not rule out several alternative explanations of the climate-migration relationship, where weather-driven agricultural shocks act indirectly on migration. For example, studies trying to establish a link between weather-induced changes in agricultural productivity and migration seldom carefully control for other concurrent mechanisms, such as conflicts and wars, criminal activities, or political instability, all of which are possible channels through which weather-induced agricultural shocks might affect migration in developing countries.

A similar remark can be made when the researcher, instead of focusing on the agricultural channel, takes into consideration the broader and more complex issue of food security. In the current empirical literature on climate change and migration, food security unfortunately is still a largely overlooked dimension. Thus, food security issues should be taken carefully into consideration in the debate between climate change and migration, with a focus on urban, rather than rural, households.

A related significant message conveyed by this survey is that the chain linking climate-driven changes in agriculture and migration is highly complex and possibly depends on several socio-economic, demographic, and political drivers. As underlined by some recent papers, several links tend to be location-specific, making it difficult to generalize many results. By focusing on 
the local interplay of these multiple drivers, future research will better our understanding of the contexts in which weather variability and climate change might increase migration through agriculture and other channels. In this regard, special attention should be paid to developing a research agenda based on a careful and smart data collection, as well as on the use of quasi-experimental methods, capable of eventually informing us of the existence of causal links in the climate-agriculture-migration relationship.

Author Contributions: Chiara Falco and Alessandro Olper designed the research as well as collected and analyzed the data. Chiara Falco wrote Sections 3.1, 3.2 and 4.1; Franco Donzelli wrote the introductions to Sections 3 and 4; Alessandro Olper wrote Sections 2.1-2.3 and 4.2. All three authors wrote Sections 1 and 5 jointly and read and approved the final manuscript.

Acknowledgments: Falco developed this research within a grant from the University of Milano under the title "Climate Change Econometrics and Agriculture".

Conflicts of Interest: The authors declare no conflict of interest.

\section{References}

1. United Nations, Department of Economic and Social Affairs, Population Division. International Migration Report 2015; United Nations: New York, NY, USA, 2016.

2. Stern, N. The Economics of Climate Chance; The Stern Review; Cambridge University Press: Cambridge, UK, 2007, ISBN 9780521700801.

3. IPCC. Contribution of Working Groups I, II and III to the Fourth Assessment Report of the Intergovernmental Panel on Climate Change; Climate Change 2007: Synthesis Report; IPCC: Geneva, Switzerland, 2008, ISBN 929169122-4.

4. Tacoli, C. Not Only Climate Change: Mobility, Vulnerability and Socioeconomic Transformations in Environmentally-fragile Areas of Bolivia, Senegal and Tanzania; International Institute for Environment and Development: London, UK, 2011. Available online: http://pubs.iied.org/10590IIED.html (accessed on 25 February 2018).

5. Black, R.; Adger, W.N.; Arnell, N.W.; Dercon, S.; Geddes, A.; Thomas, D. The effect of environmental change on human migration. Glob. Environ. Chang. 2011, 21, S3-S11. [CrossRef]

6. Kanta, K.R.; de Sherbinin, A.; Jones, B.; Bergmann, J.; Clement, V.; Ober, K.; Schewe, J.; Adamo, S.; McCusker, B.; Heuser, S.; et al. Groundswell: Preparing for Internal Climate Migration; The World Bank: Washington, DC, USA, 2018.

7. McLeman, R.; Smit, B. Migration as an adaptation to climate change. Clim. Chang. 2006, 76, 31-53. [CrossRef]

8. Drabo, A.; Mbaye, L.M. Natural disasters, migration and education: An empirical analysis in developing countries. Environ. Dev. Econ. 2015, 20, 767-796. [CrossRef]

9. Mbaye, L.M. Climate change, natural disasters, and migration. IZA World Labor 2017, 346, 1-10. [CrossRef]

10. Cai, R.; Feng, S.; Oppenheimer, M.; Pytlikova, M. Climate variability and international migration: The importance of the agricultural linkage. J. Environ. Econ. Manag. 2016, 79, 135-151. [CrossRef]

11. FAO. Migration, Agriculture and Climate Change. Reducing Vulnerabilities and Enhancing Resilience; Technical Report; United Nations: Rome, Italy, 2017.

12. Samberg, L.H.; Gerber, S.J.; Ramankutty, N.; Mario Herrero, M.; West, P. Subnational distribution of average farm size and smallholder contributions to global food production. Environ. Res. Lett. 2016, 11, 124010. [CrossRef]

13. Glaser, R.; Himmelsbach, I.; Bösmeier, A. Climate of migration? How climate triggered migration from southwest Germany to North America during the 19th century. Clim. Past. 2017, 13, 1573-1592. [CrossRef]

14. Hornbeck, R. The enduring impact of the American Dust Bowl: Short- and long-run adjustments to environmental catastrophe. Am. Econ. Rev. 2012, 102, 1477-1507. [CrossRef]

15. Borjas, G.J. Assimilation, Changes in Cohort Quality, and the Earnings of Immigrants. J. Labor Econ. 1985, 3, 463-489. [CrossRef]

16. Blanc, E.; Reilly, J. Approaches to assessing climate change impacts on agriculture: An overview of the debate. Rev. Environ. Econ. Policy 2017, 11, 247-257. [CrossRef]

17. Antle, J.M.; Stöckle, C.O. Climate impacts on agriculture: Insights from agronomic-economic analysis. Rev. Environ. Econ. Policy 2017, 11, 299-318. [CrossRef] 
18. Nelson, G.C.; van der Mensbrugghe, D.; Ahammad, H.; Blanc, E.; Calvin, K.; Hasegawa, T.; Havlik, P.; Heyhoe, E.; Kyle, P.; Lotze-Campen, H.; et al. Agriculture and climate change in global scenarios: Why don't the models agree. Agric. Econ. 2014, 45, 85-101. [CrossRef]

19. Stevanović, M.; Popp, A.; Lotze-Campen, H.; Dietrich, J.P.; Müller, C.; Bonsch, M.; Schmitz, C.; Bodirsky, B.L.; Humpenöder, F.; Weindl, I. The impact of high-end climate change on agricultural welfare. Sci. Adv. 2016, 2, e1501452. [CrossRef] [PubMed]

20. Dell, M.; Jones, B.F.; Olken, B.A. What do we learn from the weather? The new climate-economy literature. J. Econ. Lit. 2014, 52, 740-798. [CrossRef]

21. Moore, F.C.; Baldos, U.L.C.; Hertel, T. Economic impacts of climate change on agriculture: A comparison of process-based and statistical yield models. Environ. Res. Lett. 2017, 12, 065008. [CrossRef]

22. Pindyck, R.S. The Use and Misuse of Models for Climate Policy; NBER Working Paper No. 21097; National Bureau of Economic Research: Cambridge, MA, USA, 2015.

23. Lobell, D.B.; Asseng, S. Comparing estimates of climate change impacts from process-based and statistical crop models. Environ. Res. Lett. 2017, 12, 15001. [CrossRef]

24. Ishinabe, N.; van der Mensbrugghe, D. Quantifying Climate Change Impacts on Migration and Food Security: CGE Analyses for the World's 103 Regions under the $2{ }^{\circ} \mathrm{C}$ scenario. In Proceedings of the 20th Annual Conference on Global Trade Analysis, Purdue University, West Lafayette, IN, USA, 7-9 June 2017.

25. Mendelsohn, R.; Nordhaus, W.D.; Shaw, D. The impact of global warming on agriculture: A Ricardian analysis. Am. Econ. Rev. 1994, 84, 753-771.

26. Mendelsohn, R.O.; Massetti, E. The use of cross-sectional analysis to measure climate impacts on agriculture: Theory and evidence. Rev. Environ. Econ. Policy 2017, 11, 280-298. [CrossRef]

27. Deschenes, O.; Greenstone, M. The economic impacts of climate change: Evidence from agricultural output and random fluctuations in weather. Am. Econ. Rev. 2007, 97, 354-385. [CrossRef]

28. Di Falco, S.; Veronesi, M.; Yesuf, M. Does adaptation to climate change provide food security? Micro perspective from Ethiopia. Am. J. Agric. Econ. 2011, 93, 829-846. [CrossRef]

29. Schlenker, W.; Hanemann, W.M.; Fisher, A.C. The impact of global warming on US agriculture: An econometric analysis of optimal growing conditions. Rev. Econ. Stat. 2006, 88, 113-125.

30. Schlenker, W.; Roberts, M.J. Nonlinear temperature effects indicate severe damages to U.S. crop yields under climate change. Proc. Natl. Acad. Sci. USA 2009, 106, 15594-15598. [CrossRef] [PubMed]

31. Wooldridge, J.M. Introductory Econometrics: A Modern Approach; Thomson/South-Western: Mason, OH, USA, 2006.

32. Hsiang, S. Climate econometrics. Ann. Rev. Resour. Econ. 2016, 8, 43-75. [CrossRef]

33. Blanc, E.; Schlenker, W. The Use of Panel Models in Assessments of Climate Impacts on Agriculture. Rev. Environ. Econ. Policy 2017, 11, 258-279. [CrossRef]

34. Schlenker, W. Inter-Annual Weather Variation and Crop Yields; Working Paper; Columbia University: New York, NY, USA, 2006.

35. Jones, B.F.; Olken, B.A. Climate shocks and exports. Am. Econ. Rev. 2010, 100, 454-459. [CrossRef]

36. Dell, M.; Jones, B.F.; Olken, B.A. Temperature and Income: Reconciling New Cross-Sectional and Panel Estimates. Am. Econ. Rev. 2009, 99, 198-204. [CrossRef]

37. Dell, M.; Jones, B.F.; Olken, B.A. Temperature shocks and economic growth: Evidence from the last half century. Am. Econ. J. Macroecon. 2012, 4, 66-95. [CrossRef]

38. Auffhammer, M.; Schlenker, W. Empirical studies on agricultural impacts and adaptation. Energy Econ. 2014, 46, 555-561. [CrossRef]

39. Burke, M.; Hsiang, S.M.; Miguel, E. Global non-linear effect of temperature on economic production. Nature 2015, 527, 235-239. [CrossRef] [PubMed]

40. Schlenker, W.; Lobell, D.B. Robust negative impacts of climate change on African agriculture. Environ. Res. Lett. 2010, 5, 014010. [CrossRef]

41. Lobell, D.B.; Schlenker, W.; Costa-Roberts, J. Climate trends and global crop production since 1980. Science 2011, 333, 616-620. [CrossRef] [PubMed]

42. Falco, C.; Galeotti, M.; Olper, A. Climate Change, Agriculture and Migration: Is There a Causal Relationship? IEFE Working Paper no. 100; Bocconi University: Milano, Italy, 2018.

43. Burke, M.; Emerick, K. Adaptation to climate change: Evidence from US agriculture. Am. Econ. J. Econ. Policy 2016, 8, 106-140. [CrossRef] 
44. Lobell, D.B. Climate change adaptation in crop production: Beware of illusions. Glob. Food Secur. 2014, 3 , 72-76. [CrossRef]

45. Lemoine, D. Expect above Average Temperatures: Identifying the Economic Impacts of Climate Change; NBER Working Papers 23549; National Bureau of Economic Research: Cambridge, MA, USA, 2017.

46. Shrader, J. Expectations and Adaptation to Environmental Risks; Job Market Paper; University of California San Diego: San Diego, CA, USA, 2017.

47. Deryugina, T.; Hsiang, S. The Marginal Product of Climate; NBER Working Paper 24072; National Bureau of Economic Research: Cambridge, MA, USA, 2017.

48. Chetty, R. Sufficient statistics for welfare analysis: A bridge between structural and reduced-form methods. Annu. Rev. Econ. 2009, 1, 451-488. [CrossRef]

49. Gray, C.; Wise, E. Country-specific effects of climate variability on human migration. Clim. Chang. 2016, 135, 555-568. [CrossRef] [PubMed]

50. Obokata, R.; Veronis, L.; McLeman, R. Empirical research on international environmental migration: A systematic review. Popul. Environ. 2014, 36, 111-135. [CrossRef] [PubMed]

51. Stark, O.; Bloom, D.E. The new economics of labor migration. Am. Econ. Rev. 1985, 75, 173-178.

52. Gray, C.; Mueller, V. Drought and Population Mobility in Rural Ethiopia. World Dev. 2012, 40, $134-145$. [CrossRef] [PubMed]

53. Beine, M.; Parsons, C. Climatic factors as determinants of international migration. Scand. J. Econ. 2015, 117, 723-767. [CrossRef]

54. Cattaneo, C.; Peri, G. The migration response to increasing temperatures. J. Dev. Econ. 2016, 122, $127-146$. [CrossRef]

55. Marchiori, L.; Maystadt, J.F.; Schumacher, I. The impact of weather anomalies on migration in sub-Saharan Africa. J. Environ. Econ. Manag. 2012, 63, 355-374. [CrossRef]

56. McMillan, M.S.; Rodrik, D. Globalization, Structural Change and Productivity Growth; NBER Working Paper 17143; National Bureau of Economic Research: Cambridge, MA, USA, 2011.

57. Barrios, S.; Bertinelli, L.; Strobl, E. Climatic change and rural-urban migration: The case of sub-Saharan Africa. J. Urban Econ. 2006, 60, 357-371. [CrossRef]

58. Findley, S.E. Does drought increase migration? A study of migration from rural Mali during the 1983-1985 drought. Int. Migr. Rev. 1994, 28, 539-553. [CrossRef] [PubMed]

59. Henry, S.; Schoumaker, B.; Beauchemin, C. The impact of rainfall on the first out-migration: A multi-level event-history analysis in Burkina Faso. Popul. Environ. 2004, 25, 423-460. [CrossRef]

60. Afifi, T.; Liwenga, E.; Kwezi, L. Rainfall-induced crop failure, food insecurity and out-migration in Same-Kilimanjaro, Tanzania. Clim. Dev. 2014, 6, 53-60. [CrossRef]

61. Pritchett, L. Let Their People Come: Breaking the Gridlock on International Labor Mobility; Center for Global Development: Washington, DC, USA, 2006, ISBN 1-933286-10-5.

62. Nawrotzki, R.J.; Hunter, L.M.; Runfola, D.M.; Riosmena, F. Climate change as a migration driver from rural and urban Mexico. Environ. Res. Lett. 2015, 10, 114023. [PubMed]

63. Farré, L.; Fasani, F. Media exposure and internal migration-Evidence from Indonesia. J. Dev. Econ. 2013, 102, 48-61. [CrossRef]

64. McLeman, R.A.; Ploeger, S.K. Soil and its influence on rural drought migration: Insights from Depression-era Southwestern Saskatchewan, Canada. Popul. Environ. 2012, 33, 304-332. [CrossRef]

65. Mueller, V.; Gray, C.; Kosec, K. Heat stress increases long-term human migration in rural Pakistan. Nat. Clim. Chang. 2014, 4, 182-185. [CrossRef] [PubMed]

66. Abu, M.; Codjoe, S.N.A.; Sward, J. Climate change and internal migration intentions in the forest-savannah transition zone of Ghana. Popul. Environ. 2014, 35, 341-364. [CrossRef]

67. Feng, S.; Oppenheimer, M.; Schlenker, W. Weather Anomalies, Crop Yields and Migration in the US Corn Belt; NBER Working Paper w17734; National Bureau of Economic Research: Cambridge, MA, USA, 2013.

68. Bohra-Mishra, P.; Oppenheimer, M.; Hsiang, S.M. Nonlinear permanent migration response to climatic variations but minimal response to disasters. Proc. Natl. Acad. Sci. USA 2014, 111, 9780-9785. [CrossRef] [PubMed]

69. Poston, D.L.; Zhang, L.; Gotcher, D.J.; Gu, Y. The effect of climate on migration: United States, $1995-2000$. Soc. Sci. Res. 2009, 38, 743-753. [CrossRef] [PubMed] 
70. Hassani-Mahmooei, B.; Parris, B.W. Climate change and internal migration patterns in Bangladesh: An agent-based model. Environ. Dev. Econ. 2012, 17, 763-780. [CrossRef]

71. Salauddin, M.; Zaman, A. Nature and extent of population displacement due to climate change triggered disasters in south-western coastal region of Bangladesh. Int. J. Clim. Chang. Strateg. Manag. 2012, 4, 54-65. [CrossRef]

72. World Urbanization Prospects. The 2014 Revision; United Nations: New York, NY, USA, 2015, ISBN 978-92-1-151517-6.

73. Kubik, Z.; Maurel, M. Weather shocks, agricultural production and migration: Evidence from Tanzania. J. Dev. Stud. 2016, 52, 665-680. [CrossRef]

74. Thiede, B.; Gray, C.; Mueller, V. Climate variability and inter-provincial migration in South America, 1970-2011. Glob. Environ. Chang. 2016, 41, 228-240. [CrossRef] [PubMed]

75. Bohra-Mishra, P.; Oppenheimer, M.; Cai, R.; Feng, S.; Licker, R. Climate variability and migration in the Philippines. Popul. Environ. 2017, 38, 286-308. [CrossRef] [PubMed]

76. Dillon, A.; Mueller, V.; Salau, S. Migratory responses to agricultural risk in northern Nigeria. Am. J. Agric. Econ. 2011, 93, 1048-1061. [CrossRef]

77. Özden, Ç.; Parsons, C.R.; Schiff, M.; Walmsley, T.L. Where on earth is everybody? The evolution of global bilateral migration 1960-2000. World Bank Econ. Rev. 2011, 25, 12-56. [CrossRef]

78. Backhaus, A.; Martinez-Zarzoso, I.; Muris, C. Do climate variations explain bilateral migration? A gravity model analysis. IZA J. Migr. 2015, 4, 1-15. [CrossRef]

79. Coniglio, N.; Pesce, G. Climate variability and international migration: An empirical analysis. Environ. Dev. Econ. 2015, 20, 434-468. [CrossRef]

80. Maurel, M.; Tuccio, M. Climate Instability, Urbanization and International Migration. J. Dev. St. 2016, 52, 735-752. [CrossRef]

81. Anderson, J.E.; van Wincoop, E. Trade Costs. J. Econ. Lit. 2004, 42, 691-751. [CrossRef]

82. Nawrotzki, R.J.; Bakhtsiyarava, M. International climate migration: Evidence for the climate inhibitor mechanism and the agricultural pathway. Popul. Space Place. 2017, 23, 1-16. [CrossRef] [PubMed]

83. Gray, C.L.; Mueller, V. Natural disasters and population mobility in Bangladesh. Proc. Natl. Acad. Sci. USA 2012, 109, 6000-6005. [CrossRef] [PubMed]

84. McGuirk, E.; Burke, M. The Economic Origins of Conflict in Africa; NBER Working Paper 23056; National Bureau of Economic Research: Cambridge, MA, USA, 2017.

85. Porter, J.J.; Dessai, S.; Tompkins, E.L. What do we know about UK household adaptation to climate change? A systematic review. Clim. Chang. 2014, 127, 371-379. [CrossRef] [PubMed]

86. Gray, C. Environment, land and rural out-migration in the southern Ecuadorian Andes. World Dev. 2009, 37, 457-468. [CrossRef]

87. Gray, C.; Bilsborrow, R. Environmental influences on human migration in rural Ecuador. Demography 2013, 50, 1217-1241. [CrossRef] [PubMed]

88. Cattaneo, C.; Massetti, E. Migration and Climate Change in Rural Africa; Fondazione Eni Enrico Mattei: Milano, Italy, 2015.

89. Alem, Y.; Maurel, M.; Millock, K. Migration as an Adaptation Strategy to Weather Variability: An Instrumental Variables Probit Analysis; Working Paper in Economics n. 665; University of Gothenburg: Göteborg, Sweden, 2016.

90. Bazzi, S. Wealth Heterogeneity and the Income Elasticity of Migration. Am. Econ. J. Appl. Econ. 2017, 9, 219-255. [CrossRef]

91. Rose, E. Ex Ante and Ex Post Labour Supply Response to Risk in a Low Income Area. J. Dev. Econ. 2001, 64, 371-388. [CrossRef]

92. Iqbal, K.; Roy, P.K. Climate change, agriculture and migration: Evidence from Bangladesh. Clim. Chang. Econ. 2015, 6, 1550006. [CrossRef]

93. Mastrorillo, M.; Licker, R.; Bohra-Mishra, P.; Fagiolo, G.; Estes, L.D.; Oppenheimer, M. The influence of climate variability on internal migration flows in South Africa. Glob. Environ. Chang. 2016, 39, 155-169. [CrossRef]

94. Crush, J. Linking Food Security, Migration and Development. Int. Migr. 2013, 51, 62-75. [CrossRef]

95. Zezza, A.; Carletto, C.; Davis, B.; Winters, P. Assessing the impact of migration on food and nutrition security. Food Policy 2011, 36, 1-6. [CrossRef] 
96. Feng, S.; Krueger, A.B.; Oppenheimer, M. Linkages among climate change, crop yields and Mexico-US cross-border migration. Proc. Natl. Acad. Sci. USA 2010, 107, 14257-14262. [CrossRef] [PubMed]

97. Auffhammer, M.; Vincent, J.R. Unobserved time effects confound the identification of climate change impacts. Proc. Natl. Acad. Sci. USA 2012, 109, 11973-11974. [CrossRef] [PubMed]

98. Missirian, A.; Schlenker, W. Asylum applications respond to temperature fluctuations. Science 2017, 358, 1610-1614. [CrossRef] [PubMed]

2018 by the authors. Licensee MDPI, Basel, Switzerland. This article is an open access article distributed under the terms and conditions of the Creative Commons Attribution (CC BY) license (http://creativecommons.org/licenses/by/4.0/). 